\title{
Modelling the dynamics of snow cover, soil frost and surface ice in Norwegian grasslands
}

\author{
Stig Morten Thorsen, ${ }^{1,2}$ Anne-Grete Roer ${ }^{3}$ \& Marcel van Oijen ${ }^{4}$ \\ 1 Grassland and Landscape Division, Norwegian Institute for Agricultural and Environmental Research, Postvegen 213, NO-4353 Klepp Stasjon, \\ Norway \\ 2 Department of Mathematical Sciences and Technology, Norwegian University of Life Sciences, PO Box 5003, NO-1432 Ås, Norway \\ 3 Plant Health and Plant Protection Division, Norwegian Institute for Agricultural and Environmental Research, Høgskoleveien 7, NO-1432, Norway \\ 4 Centre for Ecology and Hydrology, Edinburgh, Natural Environment Research Council, Bush Estate, Penicuik, EH26 0QB, UK
}

\begin{abstract}
Keywords
Calibration; frost depth; ice cover; modelling; sensitivity analysis; snow cover.
\end{abstract}

\section{Correspondence}

Stig Morten Thorsen, Grassland and Landscape Division, Norwegian Institute for Agricultural and Environmental Research, Postvegen 213, NO-4353 Klepp Stasjon, Norway. E-mail: stig.thorsen@bioforsk.no

doi:10.1111/j.1751-8369.2010.00157.x

\begin{abstract}
Studying the winter survival of forage grasses under a changing climate requires models that can simulate the dynamics of soil conditions at low temperatures. We developed a simple model that simulates depth of snow cover, the lower frost boundary of the soil and the freezing of surface puddles. We calibrated the model against independent data from four locations in Norway, capturing climatic variation from south to north (Arctic) and from coastal to inland areas. We parameterized the model by means of Bayesian calibration, and identified the least important model parameters using the sensitivity analysis method of Morris. Verification of the model suggests that the results are reasonable. Because of the simple model structure, some overestimation occurs in snow and frost depth. Both the calibration and the sensitivity analysis suggested that the snow cover module could be simplified with respect to snowmelt and liquid water content. The soil frost module should be kept unchanged, whereas the surface ice module should be changed when more detailed topographical data become available, such as better estimates of the fraction of the land area where puddles may form.
\end{abstract}

Grasslands are important components of Norwegian terrestrial ecosystems. In order to investigate the impacts of climate change, parts of the Norwegian research programme Climate Change Effects on Winter Survival of Perennial Forage Crops and Winter Wheat, and Plant Diseases and Weed Growth and Control at High Latitudes (WINSUR) are dedicated to developing a grassland model to study the winter survival of different crops. The grassland model, currently simulating the regrowth dynamics of timothy (Phleum pratense L.), has been developed by van Oijen, Höglind et al. (2005). The same model will be adapted to simulate the regrowth dynamics of perennial ryegrass (Lolium perenne L.). During the winter, a significant number of plants may die as a result of frost, ice encapsulation, and other physical and biological stresses (Larsen 1994). Snow cover provides insulation from lethal freezing temperatures, while also reducing the amount of photosynthetically active radiation at plant level. However, a more variable winter climate in Norway
(Beldring et al. 2008) may lead to less snow cover, and may thereby increase plant exposure to killing frosts (Bélanger et al. 2002).

If the ground is frozen, water (rain or snowmelt) can accumulate in small depressions, freeze and cause plants to be encapsulated in ice. Ice encasement can severely reduce gas exchange between the plant and the surrounding atmosphere, leading to a transition from aerobic to anaerobic respiration, and to the accumulation of respiration products (especially $\mathrm{CO}_{2}$ ) to toxic levels (Gudleifsson \& Larsen 1993).

In order to make predictions about the effects of climate change on plant performance over more than one growing season, the grassland model needs an additional set of functions to describe the winter survival of the sward. The grassland model must be able to simulate effects of winter climate on soil and soil surface processes. The main objective of this work is to develop a simple winter module that can easily be incorporated into the 
existing grassland model. Therefore, the structure of the winter module needs to be kept as simple as possible.

Regarding the simulation of winter climate effects on soil and soil surface conditions (e.g., snow cover and soil frost), the literature provides examples of different approaches (Benoit \& Mostaghimi 1985; Flerchinger \& Saxton 1989; Jordan 1991; Vehvilainen 1992; Melloh 1999; Engeset et al. 2000; DeGaetano et al. 2001; Jansson \& Karlberg 2001; Kokkonen et al. 2006). We implemented and tested different algorithms for snow cover and soil frost that have already been applied to Nordic conditions. Based on preliminary modelling work, including site-specific model calibration, we developed a new snow module using ideas from a snow model currently being used by the Norwegian Water Resources and Energy Directorate (NVE) (Engeset et al. 2000). The NVE model has 10 parameters, and is used throughout Norway for operational snow forecasts. This model simulates snow accumulation based on daily precipitation rates and daily mean air temperature. Snowmelt is a function of a degree-day temperature index, described by a sinusoidal curve and daily mean air temperature. The NVE model is mainly designed for hydrological purposes (hydroelectricity production and spring flood warnings), and thus simulates the liquid water equivalent of snow water equivalent (SWE) (mm) and snowmelt run-off, but not snow depth.

Different models for simulating snow accumulation and snowmelt are described in the literature, ranging from hydrological (Jordan 1991; Engeset et al. 2000; Kokkonen et al. 2006) to combined agricultural and hydrological applications (Flerchinger \& Saxton 1989) and soil-plant-atmosphere systems (Jansson \& Karlberg 2001 ). These models simulate point estimates of a singlelayered homogeneous one-dimensional (z-direction) snow cover, whereas Jordan (1991) presents a multilayered one-dimensional snow model. Melloh (1999) provides a review of several snowmelt models. Comprehensive state-of-the-art snow models such as the COUP model (Jansson \& Karlberg 2001) with graphical user interface and the SNTHERM model (FORTRAN-77 code; Jordan 1991) are very complex and rich in parameters $(>100)$. The COUP model was considered as a potential candidate early in the project, but the model version available at that time required a special graphical user interface, and therefore could not be incorporated into the grassland model, which was developed using another programming environment (MATLAB and Simulink). The combination of a special user interface and extensive data requirements (as regards number of parameters and driving climate variables) makes it very difficult to incorporate state-of-the-art snow cover and soil frost models as sub-modules into other models. The ability to incorporate a snow and soil frost model into a larger grassland model was our main motivation for developing a new model. Our proposed model is simple: it only requires nine calibrated parameters and two input variables to simulate daily values of the depths of snow cover, soil frost and surface ice, and the temperature between the soil surface and the snow cover.

A study comparing four models simulating soil frost (Kennedy \& Sharratt 1998)-the two finite difference models SHAW and SOIL, and two energy balance models-concluded that the simpler energy balance models generally overestimate the frost depth. However, one weakness of all four models compared by Kennedy $\delta$ Sharratt (1998) is the estimation of snow depth (one of the energy balance models uses snow depth as an input). Snow cover has a strong influence on the estimation of soil frost depth, e.g., through snow depth and snow density, with both affecting the thermal conductivity of the snow cover. Therefore, accurate simulation of snow cover is important for the simulation of soil frost depth.

As regards modelling the formation of ice on the soil surface, we did not find examples in the literature of models simulating this process or ice encapsulation of the ground vegetation.

Following the conclusions by Kennedy $\&$ Sharratt (1998), the present work describes a new model that simultaneously simulates the depths of snow, soil frost and surface ice, and explains how it was calibrated for sites across Norway using Bayesian methods. We also conducted a sensitivity analysis of the model using the Morris method, which identifies the parameters to which the model is most sensitive.

\section{Materials and methods}

\section{The snow model}

Our snow module is based on ideas presented by Melloh (1999, and references therein) and Engeset et al. (2000). Whereas snow models used for hydrological purposes usually simulate SWE, SnowFrostIce also simulates the actual depth of the snow cover $S_{\text {depth }}(\mathrm{m})$. To run SnowFrostIce, the only required meteorological inputs are daily values of mean air temperature $T_{\text {air }}\left({ }^{\circ} \mathrm{C}\right)$ and precipitation rate $P\left(\mathrm{~mm} \mathrm{~d}^{-1}\right)$. The parameters, which need to be locally calibrated, are listed in Table 1.

In SnowFrostIce, the precipitation form is determined by a threshold temperature $T_{\mathrm{rs}}\left({ }^{\circ} \mathrm{C}\right)$. If $T_{\text {air }}>T_{\mathrm{rs}}$, precipitation falls as rain, $P_{\mathrm{r}}\left(\mathrm{mm} \mathrm{d}^{-1}\right)$. Otherwise it falls as snow $P_{\mathrm{s}}$ $\left(\mathrm{mm} \mathrm{day}^{-1}\right)$, with density $\rho_{\mathrm{ns}}\left(\mathrm{kg} \mathrm{m}^{-3}\right)$. There is no intermediate form for sleet. The snow cover consists of water in solid state $S_{\text {dry }}(\mathrm{mm})$ (snow and ice), and liquid state $S_{\text {wet }}(\mathrm{mm})$. The threshold temperature $T_{\mathrm{mf}}\left({ }^{\circ} \mathrm{C}\right)$ determines 
Table 1 Parameter description for the SnowFrostlce model. $\boldsymbol{\theta}^{\min }$ and $\boldsymbol{\theta}^{\text {max }}$ represent parameter lower and upper boundaries; $\boldsymbol{\theta}^{\text {mode }}$ and $\boldsymbol{\theta}^{\text {def }}$ represent parameter mode and default values, respectively. When $\boldsymbol{\theta}_{i}^{\text {mode }}$ values are presented, a beta prior distribution is used for parameter $\theta_{i}$, otherwise a uniform prior distribution is assumed between $\boldsymbol{\theta}^{\min }$ and $\boldsymbol{\theta}^{\max }$.

\begin{tabular}{|c|c|c|c|c|c|c|}
\hline$\overline{\text { Symbol }}$ & Unit & $\theta_{i}^{\min }$ & $\theta_{i}^{\max }$ & $\theta_{i}^{\text {mode }}$ & $\theta_{i}^{\text {def }}$ & References \\
\hline$T_{\mathrm{rs}}$ & ${ }^{\circ} \mathrm{C}$ & -5 & 5 & 0.5 & 0.5 & Engeset et al. (2000) \\
\hline$T_{\mathrm{mf}}$ & ${ }^{\circ} \mathrm{C}$ & -5 & 5 & 0.5 & 0.5 & Engeset et al. (2000) \\
\hline$\xi$ & 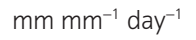 & 0 & 1 & - & 0.02 & Thorsen \& Haugen (2007) \\
\hline$\Delta \mathrm{K}_{\max }$ & $m m^{\circ} \mathrm{C}^{-1} \mathrm{day}^{-1}$ & 0 & 5 & 1.25 & 1.25 & Engeset et al. (2000) \\
\hline$K_{\min }$ & $m m{ }^{\circ} \mathrm{C}^{-1}$ day $^{-1}$ & 0 & 5 & 2 & 2 & Engeset et al. (2000) \\
\hline$S W_{r f}$ & $m m^{\circ} \mathrm{C}^{-1} \mathrm{day}^{-1}$ & 0 & 5 & 0.01 & 0.01 & Engeset et al. (2000) \\
\hline$\rho_{\mathrm{ns}}$ & $\mathrm{kg} \mathrm{m} \mathrm{m}^{-3}$ & 10 & 250 & - & 100 & Judson \& Doesken (2000) \\
\hline$S W_{\text {ret }}$ & $\mathrm{mm} \mathrm{mm}^{-1}$ & 0 & 1 & 0.1 & 0.1 & Engeset et al. (2000) \\
\hline$\lambda_{\mathrm{fs}}$ & $\mathrm{J} \mathrm{m}^{-1}{ }^{\circ} \mathrm{C}^{-1} \mathrm{day}^{-1}$ & $8.6 \times 10^{4}$ & $21.6 \times 10^{4}$ & - & $17.3 \times 10^{4}$ & Jansson \& Karlberg (2001) \\
\hline
\end{tabular}

whether snow is in the process of melting $M\left(\mathrm{~mm} \mathrm{day}^{-1}\right)$, when $T_{\text {air }}>T_{\mathrm{mf}}$, or when liquid water within the snow cover is in the process of refreezing $M_{\mathrm{rf}}\left(\mathrm{mm}\right.$ day $\left.{ }^{-1}\right)$, when $T_{\text {air }}<T_{\mathrm{mf}}$. The numerical values of $T_{\mathrm{rs}}$ and $T_{\mathrm{mf}}$ are sampled from the posterior distribution obtained in the Bayesian calibration. As the model is calibrated locally, the estimates of $T_{\mathrm{rs}}$ and $T_{\mathrm{mf}}$ are different for each location. Instead of using a constant melt rate (mm snowmelt per degree celsius and day, also known as the degree-day temperature index method), we use a degree-day temperature index $K\left(\mathrm{~mm}^{\circ} \mathrm{C}^{-1} \mathrm{day}^{-1}\right)$, which is described by a sinusoidal curve (see Eqn. 4). The reason for describing $K$ by a sinusoidal curve is to incorporate the seasonal variation. Incoming radiation increases and the albedo of the snow cover decreases in the spring. Thus $K$ increases in spring. In Norway, located between latitudes $58^{\circ}$ and $71^{\circ} \mathrm{N}$ in the Northern Hemisphere, the dates of the solstice are 21 December and 21 June. The sinusoidal curve is therefore defined as having a period of 1 year, with a trough, termed $K_{\min }\left(\mathrm{mm}^{\circ} \mathrm{C}^{-1}\right.$ day $\left.^{-1}\right)$, on 21 December, and a crest, termed $K_{\max }\left(\mathrm{mm}^{\circ} \mathrm{C}^{-1} \mathrm{day}^{-1}\right)$, on 21 June. The simulated snowmelt intensity $M$ is proportional to the number of degrees above $T_{\mathrm{mf}}$ (see Eqn. 5). To avoid situations such as $K_{\max }<K_{\min }$ during the calibration, we replaced $K_{\max }$ by $\Delta K_{\max }=K_{\max }-K_{\min }$, and calibrated $\Delta K_{\max }$ $\left(\mathrm{mm}^{\circ} \mathrm{C}^{-1}\right.$ day $\left.^{-1}\right)$ (see Table 1$)$.

Liquid water within the snow cover may refreeze. The simulated refreezing intensity $M_{\mathrm{rf}}$ is proportional to the number of degrees below $T_{\mathrm{mf}}$ (see Eqn. 6), where $S W_{\mathrm{rf}}$ $\left(\mathrm{mm}{ }^{\circ} \mathrm{C}^{-1}\right.$ day $\left.^{-1}\right)$ is the degree-day temperature index for refreezing. We calculated the potential retention capacity of the snow cover as $S W_{\text {ret }}{ }^{*} S_{\text {dry }}$, where $S W_{\text {ret }}\left(\mathrm{mm} \mathrm{mm}^{-1}\right)$ is the retention capacity of the snow cover. The snow water equivalent, $S W E$, is defined as the sum of $S_{\text {dry }}$ and $S_{\text {wet, }}$ and the density of the snow cover $\rho_{\mathrm{s}}\left(\mathrm{kg} \mathrm{m}^{-3}\right)$ is defined as $S W E / S_{\text {depth }}$. As snow is accumulated on the surface of the snow cover, there is a rapid metamorphosis as snow crystals break down, and at lower snow depths densification occurs at a slower rate, which is largely determined by the overburden pressure (Gray \& Morland 1995). In SnowFrostIce we make the assumption that the combined effects of the metamorphosis of snow crystals and the densification of the lower snow layers is captured by the empirical compaction parameter $\xi\left(\mathrm{mm} \mathrm{mm}^{-1} \mathrm{day}^{-1}\right)$. We use the following equations (1-6) to describe the snow cover dynamics.

$$
\begin{gathered}
\frac{\Delta S_{d r y}}{\Delta t}=P_{s}+M_{r f}-M \\
\frac{\Delta S_{\text {wet }}}{\Delta t}=P_{r}+M-M_{r f} \\
\frac{\Delta S_{\text {depth }}}{\Delta t}=\frac{P_{s}}{\rho_{n s}}-\frac{M}{\rho_{s}}-\xi S_{\text {depth }} \\
\frac{\Delta K_{\max }}{2} \sin \left(\frac{2 \pi t}{365}+\frac{3}{8} \pi\right)+\left(K_{\min }+\frac{\Delta K_{\max }}{2}\right) \\
M=K\left(T_{a i r}-T_{m f}\right) \\
M_{r f}=S W_{r f}\left(T_{m f}-T_{a i r}\right)
\end{gathered}
$$

The snow model parameters to be calibrated are listed in Table 1.

\section{The soil frost model}

When modelling soil frost we use an energy balance approach. Our simple approach does not include an annual energy budget for the soil system. SnowFrostice simulates only the lower frost boundary $F_{\text {depth }}(\mathrm{m})$, resulting in one frozen soil layer ranging from the soil surface to $F_{\text {depth }}$. For the soil-water balance, we use the routines implemented in the grassland model by Höglind et al. (2001) to obtain daily values of available soil water content $x_{\mathrm{w}}\left(\mathrm{m}^{3} \mathrm{~m}^{-3}\right)$ (i.e., what is left from surplus liquid water after transpiration and evaporation is subtracted), 
which is used in the calculation of $F_{\text {depth. }}$. The soil layer is parameterized as in the grassland model. SnowFrostIce requires site-specific soil type parameters for soil water retention, but the only soil parameter to be calibrated is the thermal conductivity of the frozen soil $\lambda_{\mathrm{fs}}\left(\mathrm{J} \mathrm{m}^{-1}{ }^{\circ} \mathrm{C}^{-1} \mathrm{day}^{-1}\right)$.

Our way of estimating the lower frost boundary $F_{\text {depth }}$ is based on certain assumptions. Regarding surface temperature, we follow along the lines of the assumption made by Benoit \& Mostaghimi (1985), that in any given 24-h period, the mean surface temperature of the soil or snow cover can be approximated by the daily mean air temperature for that same period. However, instead of using the daily mean air temperature at the snow cover surface when calculating $F_{\text {depth }}$, like Benoit \& Mostaghimi (1985), whenever a snow cover is simulated we use a simulated soil surface temperature $T_{\text {surf }}\left({ }^{\circ} \mathrm{C}\right)$ from Eqn. 15 as an approximation to the soil surface temperature to incorporate the insulating effect of the snow cover. (Note to Eqn. 7: during snow-free periods we assume $T_{\text {surf }}$ can be approximated by $T_{\text {air. }}$.) We assume a unidirectional stationary flow of heat between $F_{\text {depth }}$ and the soil surface, ignoring additional heat from, e.g., lower unfrozen soil layers, percolating water, radiation and no freeze-point depression. We further assume a linear variation in soil temperature $T(z)\left({ }^{\circ} \mathrm{C}\right)$ with respect to soil depth $z(\mathrm{~m})$ in the frozen soil layer, and that all available soil water $x_{\mathrm{w}}$ within this layer freezes. It is the temperature difference between the soil surface and $F_{\text {depth }}$ that drives the process of soil frost formation in the model:

$$
T(z)=T_{\text {surf }}+z \frac{T^{*}-T_{\text {surf }}}{F_{\text {depth }}}
$$

where $T_{\text {surf }}$ is the simulated temperature just above the soil surface, $T^{*}\left({ }^{\circ} \mathrm{C}\right)$ is the temperature where soil water freezes (we assume $T^{*}=0^{\circ} \mathrm{C}$ ). Following the assumption regarding $T(z)$, Eqn. 7 is only valid when $F_{\text {depth }}>0$. We denote the heat flux density released when the soil water freezes $Q_{\mathrm{E}}\left(\mathrm{J} \mathrm{m}^{-2} \mathrm{day}^{-1}\right)$. Following an existing idea (Thorsen \& Haugen 2007), we express $Q_{\mathrm{E}}$ using the above assumptions as:

$$
Q_{E}=-x_{w} \rho_{w} L_{f} \frac{\partial F_{\text {depth }}}{\partial t}
$$

where $x_{\mathrm{w}}$ is available soil water content, $\rho_{\mathrm{w}}$ $\left(1000 \mathrm{~kg} \mathrm{~m}^{-3}\right)$ is the density of water and $L_{\mathrm{f}}\left(335 \mathrm{~kJ} \mathrm{~kg}^{-1}\right)$ is the latent heat of fusion. When the soil cools down during autumn and winter, the heat released $\left(Q_{\mathrm{E}}\right)$ when the soil frost penetrates deeper into the soil is transported through the previously frozen soil. Using Fourier's equation for heat transport in one-dimensional form, we express the heat transport through the frozen soil, termed $Q_{\mathrm{fs}}\left(\mathrm{J} \mathrm{m}^{-2}\right.$ day $\left.^{-1}\right)$, as:

$$
Q_{f s}=-\lambda_{f s} \frac{\partial T(z)}{\partial z}
$$

From the assumption of linear variation in soil temperature $T(z)$ with depth $z$ in frozen soil, we obtain $\frac{\partial T(z)}{\partial z}$ from Eqn. 7, and insert this into Eqn. 9:

$$
Q_{f s}=-\lambda_{f s} \frac{T^{*}-T_{\text {surf }}}{F_{\text {depth }}}
$$

Equating Eqns. 8 and 10 and using the assumption $T^{*}=0^{\circ} \mathrm{C}$, we obtain an algebraic expression for the rate of change in $F_{\text {depth }}$ :

$$
\frac{\partial F_{\text {depth }}}{\partial t}=-\frac{\alpha}{F_{\text {depth }}}
$$

where $\alpha=\frac{\lambda_{f s} T_{\text {surf }}}{x_{w} \rho_{w} L_{f}}$. If we neglect the diurnal variation in $T_{\text {surf }}$ and $x_{w}$, and consider Eqn. 11 as $\frac{\mathrm{d} F_{\text {depth }}}{\mathrm{d} t}=-\frac{\alpha}{F_{\text {depth }}}$, by solving this equation we can express the daily increase in frost depth as $F_{\text {depth }}^{(t+1)}=\sqrt{\left(F_{\text {depth }}^{t}\right)^{2}-2 \alpha}$. Provided $\left(F_{\text {depth }}^{(t)}\right)^{2}-2 \alpha>0$, we can express the rate of change in $F_{\text {depth }}$ as follows:

$$
\frac{\Delta F_{\text {depth }}}{\Delta t}=\frac{1}{\Delta t}\left(\sqrt{\left(F_{\text {depth }}^{(t)}\right)^{2}-2 \alpha}-F_{\text {depth }}^{(t)}\right)
$$

The presence of snow cover has an insulating effect on the soil. Following Jansson \& Karlberg (2001), we assume a steady state heat flow through the frozen soil layer and the snow cover. The heat flux density through the frozen soil $Q_{\mathrm{fs}}$ from Eqn. 10 thereby equals the heat flux density through the snow cover $Q_{\text {snow }}\left(\mathrm{J} \mathrm{m}^{-2} \mathrm{day}^{-1}\right)$ :

$$
\begin{gathered}
Q_{f s}=Q_{\text {snow }} \\
-\lambda_{f s} \frac{T^{*}-T_{\text {surf }}}{F_{\text {depth }}}=-\lambda_{s} \frac{T_{\text {surf }}-T_{\text {air }}}{S_{\text {depth }}}
\end{gathered}
$$

where $\lambda_{\mathrm{s}}\left(\mathrm{J} \mathrm{m}^{-1}{ }^{\circ} \mathrm{C}^{-1} \mathrm{day}^{-1}\right)$ is the thermal conductivity of the snow cover. The parameter $\lambda_{\mathrm{s}}$ is treated as a constant, and is not calibrated. According to Jansson $\delta$ Karlberg (2001), a reasonable estimate for the ratio $\lambda_{\mathrm{fs}} / \lambda$ in our situation is $\lambda_{\mathrm{fs}} / \lambda_{\mathrm{s}} \approx 10$. We rearrange the above equation to derive the following approximation of $T_{\text {surf: }}$ :

$$
T_{\text {surf }} \approx T_{\text {air }} /\left(1+10\left(S_{\text {depth }} / F_{\text {depth }}\right)\right)
$$

(Note: for the calculations, $F_{\text {depth }}>0$ when soil frost is present.) In the case of an existing snow cover but no soil frost $\left(F_{\text {depth }}=0\right)$, we assume $T_{\text {surf }}$ to lie around $0^{\circ} \mathrm{C}$. This assumption is in accordance with observations made by Iwata et al. (2008), and it is incorporated by an additional 
Table 2 Locations in Norway used for calibrating and validating the SnowFrostlce model. The fifth location, Karasjok, was only included in the validation, and was not used in the calibration.

\begin{tabular}{lllll}
\hline Location & Grid & Elevation (m a.s.I.) & Climate & Measurement calibration \\
\hline Kise & $60^{\circ} 77^{\prime} \mathrm{N}, 10^{\circ} 8^{\prime} \mathrm{E}$ & 127 & Interior, lake & $1993-96$ \\
Kvithamar & $63^{\circ} 49^{\prime} \mathrm{N}, 10^{\circ} 88^{\prime} \mathrm{E}$ & 40 & Coastal & $2001-03$ \\
Vågønes & $67^{\circ} 28^{\prime} \mathrm{N}, 14^{\circ} 45^{\prime} \mathrm{E}$ & 30 & Coastal & $1998-2001$ \\
Holt & $69^{\circ} 65^{\prime} \mathrm{N}, 18^{\circ} 91^{\prime} \mathrm{E}$ & 20 & Coastal & $1996-99$ \\
Karasjok & $69^{\circ} 28^{\prime} \mathrm{N}, 25^{\circ} 31^{\prime} \mathrm{E}$ & 149 & Interior & $2001-03$ \\
\hline
\end{tabular}

empirical expression preserving the insulating effect of the snow cover:

$$
T_{\text {surf }} \approx T_{\text {air }} \mathrm{e}^{\left(-\gamma S_{\text {depth }}\right)}
$$

where the empirical parameter $\gamma\left(\mathrm{m}^{-1}\right)$ is set to 65 . This $\gamma$ parameter is not calibrated.

\section{Puddle formation and infiltration of meltwater}

As we were unable to obtain topographical information for any location during this study, we assume the hypothetical field of interest to be an even, rectangular surface sloping at a low angle towards a water-blocking barrier at the lower end. The height of this barrier determines the maximum depth of the surface puddle. This maximum storage level is set to $50 \mathrm{~mm}$. Baker \& Spaans (1997) report that infiltration from puddles can occur despite the presence of a frozen soil layer of $20-40 \mathrm{~cm}$. Based on this observation, surface water (snowmelt and rain) in SnowFrostIce is allowed to infiltrate into the soil if $F_{\text {depth }}<20 \mathrm{~cm}$. This assumption is also confirmed by Iwata et al. (2008). In reality, the surface water transfers heat to the soil, and because the frozen soil initially remains cold this may create a thin ice layer at the soil surface, which impedes water infiltration and increases surface run-off (Stähli et al. 2004). Therefore, when $F_{\text {depth }}$ penetrates below $20 \mathrm{~cm}$, we assume that the soil becomes impermeable to any further infiltration, and that the surface water is re-directed to the puddle area. If the maximum depth of the barrier at the end of the field is exceeded, the additional surface water runs off. When the soil starts thawing we let the infiltration rate of the puddle water follow the thawing rate (in accordance with observations by Hayashi et al. [2003]), until $F_{\text {depth }}>20 \mathrm{~cm}$, when the remaining puddle water is drained as if the soil were unfrozen.

\section{Formation of ice layer}

When a surface puddle is formed, the water may freeze and form a basal ice layer. By regarding the puddle as an extremely dilute soil, and setting the water content to unity, we use the same approach to calculate $I_{\text {depth }}(\mathrm{mm})$ as we do for the soil frost. Provided $\left(I_{\text {depth }}^{(t)}\right)^{2}-2 \beta>0$, we get the following expression for the daily change in $I_{\mathrm{depth}}$ :

$$
\frac{\Delta I_{\text {depth }}}{\Delta t}=\frac{1}{\Delta t}\left(\sqrt{\left(I_{\text {depth }}^{(t)}\right)^{2}-2 \beta}-I_{\text {depth }}^{(t)}\right)
$$

where $\beta=\frac{\lambda_{i} T_{\text {surf }}}{\rho_{w} L_{f}}$, the thermal conductivity of ice is $\lambda_{\mathrm{i}}$ $\left(19.4 \times 10^{4} \mathrm{~J} \mathrm{~m}^{-1}{ }^{\circ} \mathrm{C}^{-1}\right.$ day $\left.^{-1}\right)$, the density of water is $\rho_{w}$ and the latent heat of fusion is $L_{\mathrm{f}}$.

\section{Description of the locations and data used in calibration}

The SnowfrostIce model was calibrated using observed depths of snow cover and the lower frost boundary. The snow cover depth was measured in $\mathrm{cm}$ in accordance with the Norwegian Meteorological Institute. The depth of the lower frost boundary was measured in cm using a frost tube, as described by DeGaetano et al. (2001) and Iwata et al. (2008). We were unable to obtain information on the accuracy of the observations. We were also unable to obtain information on normal depths of snow cover and soil frost. We therefore present values of mean air temperature and precipitation sums from autumn to spring, and frost sums. Table 2 presents a geographical description of the locations, and Tables 3-6 provide a summary of the climate for each location for the current normal period in Norway (1961-1990), and for the calibration and validation periods. For each location we calculated the following from autumn to spring (i.e., from 1 September to 30 April): the mean $2 \mathrm{~m}$ air temperature, denoted as mean $\left(T_{\text {air }}\right)$; the temperature sum for days when $T_{\text {air }}<0$, denoted as $\Sigma T_{\text {air }}$; and the sum of daily precipitation rates, denoted as $\Sigma$ Prec.

During the calibration period at Kise (Table 3), the first and third winters were both colder and had more frost compared with the normal period. The second winter was milder and had less frost. The first winter received more precipitation compared with the normal period, whereas the latter two winters were dryer. In the validation period, all winters were slightly milder and had less frost than normal: the first winter was dryer than normal, whereas the latter two were wetter. 
Table 3 Climate summary for Kise. Values are calculated for the months September-April for the current normal period in Norway (1961-1990), and for the respective calibration and validation periods. Mean $\left(T_{\text {air }}\right)\left({ }^{\circ} \mathrm{C}\right)$ is the average $2-\mathrm{m}$ air temperature, $\Sigma T_{\text {air }}\left({ }^{\circ} \mathrm{C}\right.$ day) is the temperature sum on frost days and $\Sigma$ Prec $(\mathrm{mm})$ is the recorded precipitation.

\begin{tabular}{lcccrrr}
\hline Sept-Apr & $1961-90$ & $1993 / 94$ & $1994 / 95$ & $1995 / 96$ & $1996 / 97$ & $1997 / 98$ \\
\hline Mean(Tair) & -1 & -2.5 & 1.1 & 2.2 & 0.8 & 1.2 \\
$\Sigma T_{\text {air }}$ & -761 & -1068 & -400 & -1214 & -629 & -439 \\
$\Sigma P_{\text {rec }}$ & 340 & 368 & 294 & 188 & 273 & 421 \\
\hline
\end{tabular}

Table 4 Climate summary for Kvithamar.

\begin{tabular}{lccccc}
\hline Sept-Apr & $1961-90$ & $2001 / 02$ & $2002 / 03$ & $2003 / 04$ & $2004 / 05$ \\
\hline Mean( $\left.T_{\text {air }}\right)$ & 1.5 & 3.2 & 1.7 & 3.2 & 3.3 \\
$\Sigma T_{\text {air }}$ & -269 & -272 & -385 & -245 & -225 \\
$\Sigma P_{\text {rec }}$ & 597 & 682 & 508 & 604 & 891 \\
\hline
\end{tabular}

See Table 3 for abbreviations.

Table 5 Climate summary for Vågønes.

\begin{tabular}{lcccccc}
\hline Sept-Apr & $1961-90$ & $1998 / 99$ & $1999 / 2000$ & $2000 / 01$ & $2001 / 02$ & $2002 / 03$ \\
\hline Mean $\left(T_{\text {air }}\right)$ & 1.3 & 1.9 & 2.6 & 2.3 & 2.6 & 1.2 \\
$\Sigma T_{\text {air }}$ & -284 & -323 & -264 & -368 & -330 & -372 \\
$\Sigma P_{\text {rec }}$ & 811 & 902 & 1156 & 561 & 983 & 735 \\
\hline
\end{tabular}

See Table 3 for abbreviations.

Table 6 Climate summary for Holt and Karasjok.

\begin{tabular}{lccccccc}
\hline Sept-Apr & $1961-90$ & $1996 / 97$ & $1997 / 98$ & $1998 / 99$ & $2005 / 06$ & $2006 / 07$ & $1998 / 99 *$ \\
\hline Mean(Tair) & $-0.8(-8.3)$ & -0.1 & 0.2 & 0.3 & 1.6 & 1.1 & -8.5 \\
$\Sigma T_{\text {air }}$ & $-375(-2199)$ & -468 & -483 & -432 & -317 & -322 & -2295 \\
$\Sigma P_{\text {rec }}$ & $765(172)$ & 804 & 627 & 578 & 831 & 817 & 207 \\
\hline
\end{tabular}

Values within brackets represent the normal period for the Karsjok location.

* 1998/99 represents the Karasjok location.

See Table 3 for abbreviations.

At Kvithamar (Table 4), both winters in the calibration period were milder than normal, but they had more frost. The first winter was wetter, and the second winter was dryer than normal. In the validation period, both winters were milder and wetter compared with the normal period.

At Vågønes (Table 5), all winters in the calibration period were milder compared with the normal period, but the first and third winters had more frost days, whereas there were fewer frost days in the second winter. The first two winters were wetter, and the third winter was dryer than normal. In the validation period, both winters had more frost than normal, but only the first winter was milder than normal. The first winter was wetter than normal, and the second was dryer.

At Holt (Table 6), all winters in the calibration period were milder and had more frost than normal. The first winter was wetter, whereas the latter two winters were dryer than normal. Both winters in the validation period were milder, had less frost and were wetter when compared with the normal period.

The winter in the validation period at Karasjok (Table 6) was approximately the same as the normal period, but slightly wetter.

In addition to simulating $S_{\text {depth }}$ and $F_{\text {depth }}$, SnowFrostIce simulates the thickness of ice $\left(I_{\text {depth }}\right)$ resulting from the freezing of soil surface puddles. However, data on surface ice were scarce, and there was no description of field topography available, forcing us to make assumptions on field topography. We therefore present full simulation results for only two locations: Holt in Troms county and Karasjok in Finnmark county. Based on data availability, we chose four locations for site-specific calibration of the model spanning the south-north variation in regional climate. Table 2 gives a brief description of these locations. Karasjok was not included in the calibration.

Observations of surface ice cover were scarce, and data were only available for two sites: Holt (1997/98 and 
1998/99) and Karasjok (1998/99). Ice observations from Holt came at a later stage in the project, so we had to use observations on snow cover and frost depth from the calibration period.

\section{Bayesian calibration of the SnowFrostlce model}

The SnowFrostIce model represents a simplification of different physical processes. Parameters used in processbased models have a physical meaning, but these are seldom precisely known, or are at best difficult to measure. We represented this uncertainty as a probability distribution over the parameters. Thus, if we define a parameter vector $\boldsymbol{\theta}$ for the model, then $\pi(\boldsymbol{\theta})$ is said to be a joint probability density function (pdf) expressing our initial prior belief in the parameters. Given a data set $\mathbf{D}$ of model outputs, we update the joint pdf of the parameters by applying the Bayes theorem: $\pi(\boldsymbol{\theta} \mid \mathbf{D})=\pi(\boldsymbol{\theta}) f(\mathbf{D} \mid \boldsymbol{\theta}) / f(\mathbf{D})$, where $\pi(\boldsymbol{\theta} \mid \mathbf{D})$ is the posterior distribution of $\boldsymbol{\theta}$ given the data $\mathbf{D}, f(\mathbf{D} \mid \boldsymbol{\theta})$ is the likelihood of the data given the model outputs using parameters $\boldsymbol{\theta}$, and $f(\mathbf{D})$ is a normalization constant. In the Bayesian calibration of dynamic models, a large number of model runs are carried out, often using a Markov chain Monte Carlo (MCMC) approach. We used the MCMC algorithm known as the Metropolis Random Walk. For further details on using Bayesian methods to calibrate complex models see van Oijen, Rougier et al. (2005). The target posterior distribution was the stationary distribution of the Markov chain produced by the Metropolis Random Walk.

\section{Metropolis Random Walk}

The general idea of the Metropolis Random Walk is to walk randomly through the parameter space, running the model at each visited point, eventually forming a Markov chain. The starting point of this chain, $\boldsymbol{\theta}_{0}$, is randomly chosen from the prior distributions for the parameters. A new proposal parameter vector $\boldsymbol{\theta}^{\prime}$ is then chosen based on the current parameter vector $\boldsymbol{\theta}^{\text {: }}$ :

$$
\boldsymbol{\theta}^{\prime}=\boldsymbol{\theta}^{t}+\boldsymbol{\delta}
$$

where $\boldsymbol{\delta}$ is the step length vector. It is also important that $p(\boldsymbol{\delta})=p(-\boldsymbol{\delta})$, i.e., that there is an equal probability of stepping in either direction from the current point. We then compute the so-called Metropolis ratio:

$$
r=\frac{\pi\left(\boldsymbol{\theta}^{\prime} \mid \mathbf{D}\right)}{\pi\left(\boldsymbol{\theta}^{t} \mid \mathbf{D}\right)}=\frac{\pi\left(\boldsymbol{\theta}^{\prime}\right) f\left(\mathbf{D} \mid \boldsymbol{\theta}^{\prime}\right)}{\pi\left(\boldsymbol{\theta}^{t}\right) f\left(\mathbf{D} \mid \boldsymbol{\theta}^{t}\right)}
$$

The next step is to generate a uniform random number $u \sim U(0,1)$, and to accept the proposal parameter vector $\boldsymbol{\theta}^{\prime}$ as the new $\boldsymbol{\theta}^{t+1}$ if $u \leq r$. Otherwise, let $\boldsymbol{\theta}^{t+1}=\boldsymbol{\theta}^{t}$. The chain consisting of all $\boldsymbol{\theta}^{t}$ forms our Markov chain, which is our sample from the posterior distribution.

The posterior distribution is therefore a combination of prior knowledge and new information obtained from the data using the likelihood function. Measurement errors are used in the determination of how likely a model-data mismatch might be, i.e., if the data are informative and have a sharply peaked distribution (i.e., a small variance), the resulting posterior distribution will be narrower and more peaked than the prior distribution. This indicates that the parameter uncertainty is reduced.

\section{Defining prior probability distributions of the parameters}

Based on a literature review, we defined the likely ranges $\left[\theta_{i}^{\min }, \theta_{i}^{\max }\right]$ and mode values for the nine parameters. For parameters where range and mode value were suggested, we used a beta distribution as prior. A suitable range was only found for parameters $\xi, \rho_{\mathrm{ns}}$ and $\lambda_{\mathrm{fs}}$. For these three parameters we selected a flat uniform distribution within their range $\left[\theta_{i}^{\min }, \theta_{i}^{\max }\right]$. In the calibration process we assumed the parameters to be independent a priori, implying that their joint prior distribution is equal to the product of their individual marginal pdfs. The parameters, along with their prior distributions, are presented in Table 1 .

\section{Defining the data-likelihood function}

We used measurements on snow depth and lower frost boundary for the calibration of SnowFrostIce. Specific information about the precision of the measurements was not available, so we used the same approach as van Oijen, Rougier et al. (2005), and chose the standard deviation of each measurement to be $30 \%$ of the mean value. To avoid a standard deviation of zero (if the observed variable was zero), the standard deviation was redefined as $\sigma_{i j}^{o}=\max \left(0.1 ; 0.3 \cdot \mathrm{D}_{\mathrm{ij}}\right)$ where $\mathrm{D}_{\mathrm{ij}}$ are the measurements on output $j$ at time $i$. Assuming the measurement errors to be independent and Gaussian, we used Sivia's (2006) formulation, which was slightly modified to account for model discrepancy:

$$
f(\mathbf{D} \mid \boldsymbol{\theta})=\prod_{j=1}^{G}\left[\prod_{R_{i j} \neq 0} \prod_{i=1}^{M} \frac{1}{\sigma_{i j}^{o} \sqrt{2 \pi}}\left[\frac{1-\mathrm{e}^{-R_{i j}^{2} / 2}}{R_{i j}^{2}}\right] \prod_{R_{i j}=0} \frac{1}{2 \sigma_{i j}^{o} \sqrt{2 \pi}}\right]
$$

where $\sigma_{i j}^{o}$ represent the lower bounds on the data noise, and the residual is represented by $R_{i j}=\left(\mathrm{D}_{i j}-M_{i j}(\boldsymbol{\theta}, \mathbf{X})\right) / \sigma_{i j}^{o}$, where $M_{i j}(\boldsymbol{\theta} *, \mathbf{X})$ are model outputs using input variables $\mathbf{X}$ and parameterization $\theta *$. 


\section{Determining jumps in the Metropolis Random Walk algorithm}

The step length vector $\boldsymbol{\delta}$ in the Metropolis Random Walk algorithm is very important in order to obtain convergence of the Markov chain produced, i.e., the targeted posterior distribution of the parameters. In our implementation, the new candidate value $\theta_{i}^{\prime}$ for parameter $i$ was $\theta_{i}^{\prime}=\theta_{i}^{t}+\delta_{i}$, where $\delta_{i} \sim N\left(0, a_{i}\right)$. If the elements in the step length vector $\delta$ are too small, the random walk algorithm will not move far enough from the current point in parameter space $\boldsymbol{\theta}^{t}$ when proposing a new candidate parameter vector $\boldsymbol{\theta}^{\prime}$, and consequently the acceptance rate will be too large, and vice versa. In our case, choosing $a_{i}$ so that the acceptance rate was between 0.15 and 0.5 (in accordance with Roberts 1996) was attained by trial and error. Each element $a_{i}$ of the vector $\boldsymbol{\delta}$ was chosen according to $a_{i}=c_{i}\left(\theta_{i}^{\max }-\theta_{i}^{\min }\right)$, where $c_{i}$ is a constant found by trial and error, and $\left(\theta_{i}^{\max }-\theta_{i}^{\min }\right)$ is the width of prior pdf of parameter $\theta_{\mathrm{i}}$.

\section{Determining convergence of the Markov chains}

A central issue when using an iterative simulation method such as the Metropolis Random Walk algorithm is to determine when the chain has converged to the desired posterior distribution. One option, suggested by Gelman \& Rubin (1992), is to generate multiple chains followed by calculating the scale reduction factor $\sqrt{\hat{R}}$, which is used to determine the length of the "burn-in" phase. The "burn-in" of the chain is the first part where the chain is influenced by the starting point until it reaches stationarity. We determined the "burn-in" phase to last until $\sqrt{\hat{R}}<1.2$, following Gelman (1996): when $\sqrt{\hat{R}}$ nears 1 it means that the Markov chains are essentially overlapping. We randomly sampled two starting points from the prior distribution, and used the $\sqrt{\hat{R}}$ to determine when the two chains had converged to the desired posterior distribution.

\section{Sensitivity analysis of SnowFrostlce}

When working with models, sensitivity analysis (hereafter referred to as SA) is recommended as part of the process (Kokkonen et al. 2006). For the SA to be meaningful, the practitioner should decide beforehand on how to define the importance of the parameters, i.e., the type of question the SA is expected to answer (Saltelli et al. 2008). In our case, we would like to know which of the parameters can be fixed anywhere within their prior bounds without affecting model outputs, i.e., which parameters are not important. This is helpful in relation to model simplification.
In order to identify non-important parameters in the model, we carried out a screening exercise using the improved sensitivity indices from the Morris method, as described by Campolongo et al. (2007). This method is relatively simple to implement.

The Morris method proposes two sensitivity measures, the main purpose of which are to determine the model $k$ parameters that can be considered to be (i) not important, (ii) linear and additive, or (iii) non-linear or involved in interactions with other parameters. For each of the parameters, two sensitivity measures are computed: $\mu$, which evaluates the overall influence of the parameter on the model output (main effect or elementary effect [EE]), and $\sigma$, which collectively evaluates all the higher order effects resulting from non-linearity and/or interactions with other parameters. The Morris method was originally used for parameters following uniform distributions in [0, 1]. If the $k$ parameters follow other distributions, Campolongo et al. (1999) suggest that rather than sampling directly from these distributions, the sampling should be performed in the space of the quantiles of these $k$ distributions (i.e., each parameter is discretized into $p$ levels, and each quantile $q_{\mathrm{p}}$ varies in $[0,1]$, producing a $k$-dimensional unit hypercube as the sampling space). The actual parameter values would subsequently be derived from their known distributions. In this SA of SnowFrostIce, we investigated the $k=9$ parameters from the calibration (Table 1). The input space we used was the sub-space $\Omega$ comprised of the $k$-dimensional unit hypercube of the $p=6$ equidistant quantiles in $[0,1]$ from the prior distribution of the parameters $\pi(\boldsymbol{\theta})$. Outputs from SnowFrostIce are time series, and for this SA we needed a scalar value. Thus, for the simulation runs required in the SA, we used as output the log-transformed likelihood from Eqn. 20, i.e., $\log [f(\mathbf{D} \mid \boldsymbol{\theta})]$, with the likelihood being the probability of the observed data $\mathbf{D}$ given a certain model parameterization $\boldsymbol{\theta}$.

By randomly sampling parameter vectors $\theta$ from $\Omega$, and calculating EE (for details, see Campolongo et al. 2007) for each of the nine parameters, we obtained a sample from the distribution for each EE, termed $\mathrm{EE}_{i} \sim F_{i}\left(\mu_{i}, \sigma_{i}\right)$. The sensitivity measures $\mu_{i}$ and $\sigma_{i}$ proposed by Morris are the mean and standard deviation of $F_{i}$, respectively. To estimate $\mu_{i}$ and $\sigma_{i}$, the sampling strategy proposed by Morris is to create $r$ trajectories in parameter space $\Omega$. Each of these $r$ trajectories contains $(k+1)$ points, and results in $k$ elementary effects (i.e., estimates of one EE per parameter), leading to a total of $r(k+1)$ sample points corresponding to the number of model runs required for the complete SA. A very nice stepwise presentation of this method is presented in Saltelli et al. (2008).

A high $\sigma_{i}$ value for parameter $\theta_{i}$ implies that the corresponding $\mathrm{EE}_{i}$ value for $\theta_{i}$ at one point in $\Omega$ is considerably 
different from another $\mathrm{EE}_{j}$ value $(I \neq j)$ for the same parameter $\theta_{i}$ located somewhere else in $\Omega$, i.e. that this particular EE value is influenced by the values of the other parameters or nonlinearities. A low value for $\sigma_{i}$ suggests that the $\mathrm{EE}_{i}$ value associated with $\theta_{i}$ is independent from the values of the other parameters, and thus it is not involved in interactions or nonlinearities.

To avoid type II errors of failing to identify important parameters, Campolongo et al. (2007) suggest replacing $\boldsymbol{\mu}$ by $\boldsymbol{\mu}^{*}$, an estimate of the mean of the distribution of the absolute values of the elementary effects $G_{i}$, i.e., $\left|E_{i}\right|$ $\mathrm{G}_{i}\left(\mu^{*}{ }_{i}, \sigma_{i}\right)$. To properly characterise non-influential parameters, one must therefore simultaneously consider the vectors $\boldsymbol{\mu}^{*}$ and $\boldsymbol{\sigma}$ (see Fig. 1 for SA results for the Kise site).

When conducting the SA, we tried the same approach for all locations. First, we sampled trajectories from the prior distribution and calculated $\mu^{*}$ and $\sigma$. Then, we sampled from the posterior distribution and calculated $\mu$ * and $\boldsymbol{\sigma}$. Sampling trajectories from the prior distribution gave very similar results for all sites (as did those for Kise; Fig. 1). When we sampled from the correlated posterior distribution, the results in $\mu^{*}$ and $\sigma$ were different when comparing sites. For all but one site the same non-important parameters were identified, but highly correlated parameters influenced the results. For example, at Kise, the parameter $T_{\mathrm{rs}}$ was wrongly recognized as being non-important. This illustrates that the Morris method can produce different results depending on whether the parameters are correlated or not. We did not find examples in the literature of how to handle correlated parameters when using the Morris method. $T_{\mathrm{rs}}$ is an important parameter, as was clearly shown when sampling trajectories from the prior distribution. Based

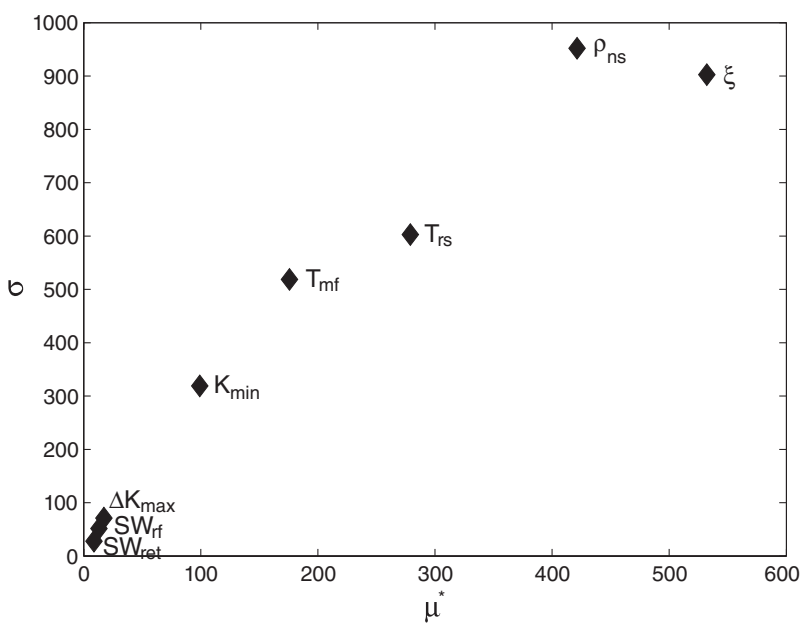

Fig. 1 Sensitivity analysis results for the location Kise showing $\mu$ * versus $\boldsymbol{\sigma}$, based on $r=100$ trajectories. Low values for both $\mu$ * and $\boldsymbol{\sigma}$ identify $S \mathbf{W}_{\text {ret, }} S W_{\text {rf }}$ and $\Delta K_{\max }$ as the least important parameters. on this observation, we decided to use the assumed uncorrelated prior distribution when sampling trajectories for the screening exercise.

\section{Model validation and predictive uncertainty}

The data sets for each location were divided in two: one part was used for calibration and the other was used for validation (Table 2 ). To evaluate the predictive uncertainty of the model after calibration, we sampled 20 parameter sets from the posterior distribution, and calculated the subsequent mean and standard deviations of the model outputs.

\section{Results}

\section{Results from the Bayesian calibration}

The main result of the Bayesian calibration procedure is the estimated joint posterior distribution of the model parameters. This correlated multidimensional joint distribution is difficult to visualize, so we present the marginal posterior distribution for single parameters.

We determined the success of the calibration by evaluating the estimated marginal posterior distributions. If they are narrower than their corresponding prior distribution, this indicates that the parameter uncertainty has been reduced. The calibration at each location used two chains of length 300 000, and a unique step length vector for that location.

The part of the Markov chains succeeding the burn-in point, which we determined as the point from where $\sqrt{\hat{R}}$ remains below 1.2, comprises the marginal posterior distribution of the parameter (Gelman 1996). The right column of Fig. 2 shows plots of $\sqrt{\hat{R}}$ for the parameters $\xi$, $\rho_{n s}$ and $T_{r s}$, and the centre column shows the estimated marginal posterior distribution for the same parameters. Panels in the left column in Fig. 2 show trace plots of the Markov chains for parameters $\xi$, $\rho_{n s}$ and $T_{r s}$ calibrated at the Kise site. These trace plots are used to verify that the two chains for each parameter stabilize around the same value, and that the posterior distribution is properly explored.

In order to visualize the marginal posterior distributions for all locations simultaneously, we fitted continuous distributions to the samples from the posterior generated by the MCMC. They are shown, together with the prior distributions, in Fig. 3. The marginal posterior distributions are either multimodal, skewed or both. It was therefore informative to present both the maximum posterior estimate and the median value of $\boldsymbol{\theta}$ $\left(\boldsymbol{\theta}_{\mathrm{MAP}}\right.$ and $\tilde{\boldsymbol{\theta}}$, respectively) from the marginal posterior 
Fig. 2 Panels in top row show results for parameter $\xi$; centre row shows results for parameter $\rho_{\mathrm{ns}}$; bottom row shows results for parameter $T_{\text {rs. }}$. Panels in the left column show trace plots of the two parallel chains (red, chain 1; black, chain 2). Panels in the centre column show the marginal posterior distribution of the parameter $\pi\left(\theta_{i} \mid \mathbf{D}\right)$. Panels in the right column show the scale reduction factor $\sqrt{\hat{R}}$, calculated at every 20th iteration.
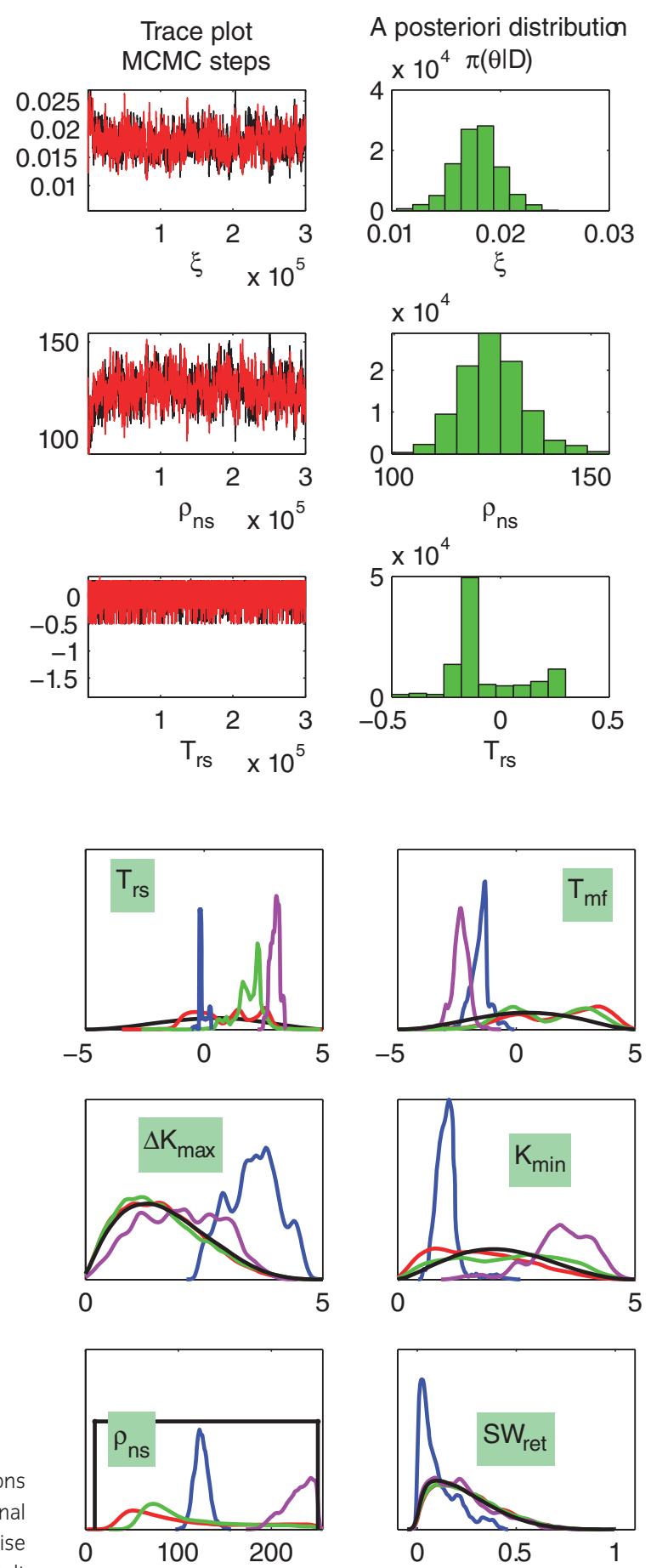
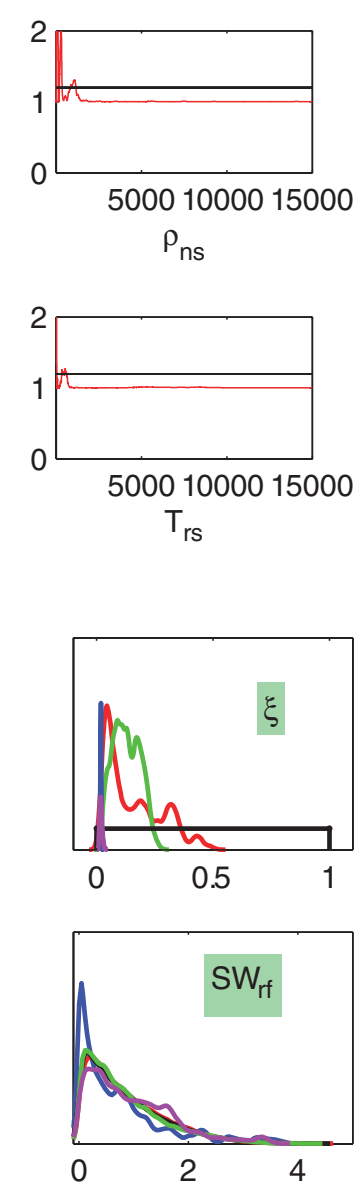

Scale reduction factor
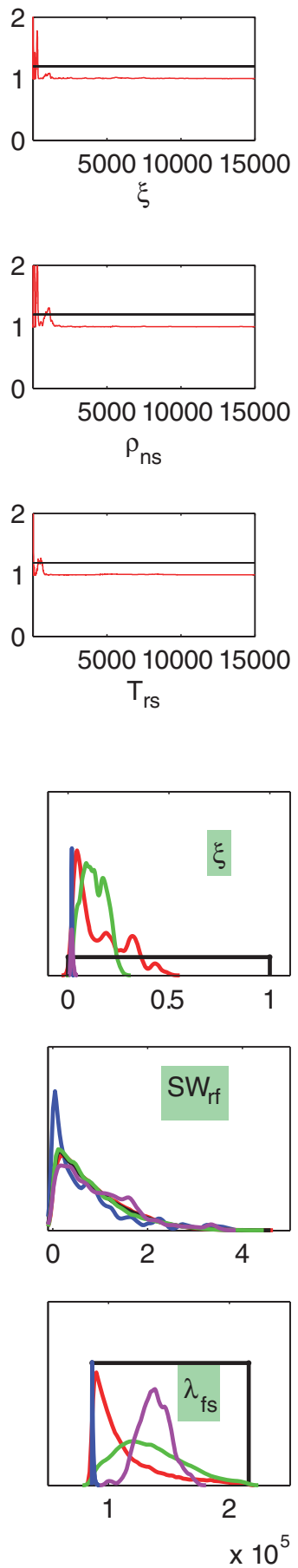

Fig. 3 Continuous density function estimations of the prior distributions (black) and the marginal posterior distributions for all locations: Kise (blue), Kvithamar (red), Vågønes (green) and Holt (magenta). distributions as summary statistics (see Table 7), complemented by plots of the marginal posterior distributions in Fig. 3 showing posterior parameter uncertainty. The parameter vector $\boldsymbol{\theta}_{\text {MAP }}$ represents the single best parameter vector at the different locations. For most of the parameters, when comparing the marginal posterior distributions in Fig. 3 with their respective prior distribution (black lines), it is clear that the calibration process reduced the prior parameter uncertainty. However, for the parameters related to liquid water in the snow cover, $S W_{\text {rf }}$ and $S W_{\text {ret, }}$ we can see that measurements on snow depth alone did not provide enough information to 
Table 7 Parameter values for SnowFrostlce that gave the highest posterior density $\boldsymbol{\theta}_{\text {MAP, }}$ and the median values $\tilde{\boldsymbol{\theta}}$ for the sites Kise, Kvithamar, Vågønes and Holt.

\begin{tabular}{|c|c|c|c|c|c|c|c|c|}
\hline \multirow{2}{*}{$\begin{array}{l}\text { Parameter } \\
\theta_{i}\end{array}$} & \multicolumn{2}{|l|}{ Kise } & \multicolumn{2}{|c|}{ Kvithamar } & \multicolumn{2}{|c|}{ Vågønes } & \multicolumn{2}{|l|}{ Holt } \\
\hline & $\theta_{\mathrm{MAP}(i)}$ & $\tilde{\theta}_{(i)}$ & $\theta_{\mathrm{MAP}(\hat{)})}$ & $\tilde{\theta}_{(i)}$ & $\theta_{\mathrm{MAP}(i)}$ & $\tilde{\theta}_{(i)}$ & $\theta_{\mathrm{MAP}(i)}$ & $\tilde{\theta}_{(i)}$ \\
\hline$T_{\mathrm{rs}}$ & -0.1 & -0.1 & -0.6 & 1 & 2.3 & 2 & 3.1 & 3 \\
\hline$T_{\mathrm{mf}}$ & -1.4 & -1.5 & 3.1 & 2.1 & 0.7 & 1.3 & -3 & -2.3 \\
\hline$\xi$ & 0.02 & 0.02 & 0.025 & 0.12 & 0.15 & 0.13 & 0.01 & 0.02 \\
\hline$\Delta K_{\max }$ & 4.5 & 3.6 & 0.79 & 1.5 & 1.8 & 1.5 & 0.5 & 2 \\
\hline$K_{\min }$ & 1.1 & 1 & 0.43 & 1.6 & 0.2 & 2.3 & 2.6 & 3.5 \\
\hline$S W_{r f}$ & 0.002 & 0.48 & 0.87 & 0.68 & 2.61 & 0.63 & 3.65 & 0.78 \\
\hline$\rho_{\mathrm{ns}}$ & 128 & 124 & 216 & 89 & 84 & 95 & 250 & 231 \\
\hline$S W_{\text {ret }}$ & 0.32 & 0.07 & 0.21 & 0.22 & 0.18 & 0.22 & 0.35 & 0.2 \\
\hline$\lambda_{\mathrm{fs}}\left(\times 10^{4}\right)$ & 8.6 & 8.8 & 12.6 & 10.3 & 17.6 & 13.1 & 13.7 & 13.8 \\
\hline
\end{tabular}

depart from our prior estimates (for the Kise site, they are more peaked). For the precipitation threshold temperature, $T_{\mathrm{rs}}$, the parameter uncertainty was least reduced at Kvithamar compared with the other locations. For $T_{\mathrm{mf}}$, the parameter uncertainty was reduced more at Kise and Holt than at Kvithamar and Vågønes. For Kvithamar, the median value of $T_{\mathrm{mf}}$ (see Table 7) was larger than the median value of $T_{\mathrm{rs}}$ (this is shown in Fig. $4 \mathrm{~b}$, where the green line is located slightly above the red line). The uncertainty in $\Delta K_{\max }$ and $K_{\min }$ was reduced for Kise and Holt, but for Kvithamar and Vågønes there was not much improvement. The parameter uncertainty was reduced for the remaining $\xi$, $\rho_{n s}$ and $\lambda_{f s}$.

\section{Results from the sensitivity analysis}

At each of the locations used in the calibration, we randomly generated $r=100$ different trajectories for the computation of EE, i.e., $r(k+1)=1000$ parameter vectors were sampled from $\Omega$, and thus 1000 model runs were used for the SA. The results were very similar for each location. Figure 1 shows the sensitivity indices $\mu^{*_{i}}$ and $\sigma_{i}$ for each parameter for the Kise site. We find the parameters $S W_{\text {ret, }} S W_{\text {rf }}$ and $\Delta K_{\text {max }}$ in the lower left-hand corner, and the remaining parameters are almost linearly spread. Inspection of histograms of the sampled parameter values suggests that the ranges of the prior intervals were adequately explored.

The parameter $\lambda_{\mathrm{fs}}$ was excluded from the SA because $S_{\text {depth }}$ affects $F_{\text {depth, }}$ and not vice versa.

\section{Validation of the model}

The SnowFrostIce model was validated at all locations used in the calibration. For each of the locations we sampled 20 parameter vectors from the posterior distribution, and calculated the mean and standard deviation of the model output. Variation in model output is shown as the mean \pm one standard deviation (Fig. 5). If the median value of $T_{\mathrm{rs}}$ is close to that of $T_{\mathrm{mf}}$ they appear as one line in the sub-figures. See Table 7 for these parameter values. The validation at the Kise site shows little variation in model output. At this site, $S_{\text {depth }}$ is overestimated for the winter of $1997 / 98$. This is as expected when considering that $T_{\text {air }}<T_{\mathrm{rs}}$ for most of the precipitation events (see Fig. 4a). Frost depth at Kise during 1997/98 is initiated earlier than observed, in addition to being slightly underestimated. $F_{\text {depth }}$ during the 1998/99 winter is overestimated: frost rates that were too high initially caused $F_{\text {depth }}$ to be shifted downwards compared with observations. The validation for Kvithamar (Fig. 5b) shows more variability in model output compared with Kise, especially towards the end of springtime for $S_{\text {depth }}$. The data points here are captured within this variation. At Vågønes (Fig. 5c), model performance for $S_{\text {depth }}$ is quite good, but $F_{\text {depth }}$ is overestimated (more severely during 2001/02 than 2002/03). At Holt (Fig. 5d), the $S_{\text {depth }}$ is overestimated during 2005/06 (as with Kise in 1997/98) because $T_{\text {air }}<T_{\mathrm{rs}}$ for most of the precipitation events of that winter. Note the events between January and May 2006 with $P>20 \mathrm{~mm}$ (Fig. 4d), where precipitation is simulated as snow. $F_{\text {depth }}$ looks reasonably accurate, but a complete thaw is predicted too early for both validation years. Variation in model output is in general higher for Kvithamar and Holt than for Vågønes and Kise. Figure 6 shows all output (snow cover, soil frost and surface ice) for Holt (1997/98) and Karasjok (1998/99). We had no data to calibrate SnowFrostIce for Karasjok. For Karasjok, we sampled the parameter values from $\pi(\boldsymbol{\theta} \mid \mathbf{D})$ obtained for Kise, as both locations have an interior climate. Holt and Karasjok were the only locations where ice observations were available.

\section{Discussion and conclusions}

In this paper we present a new model for the simulation of snow depth, soil frost depth and depth of surface 

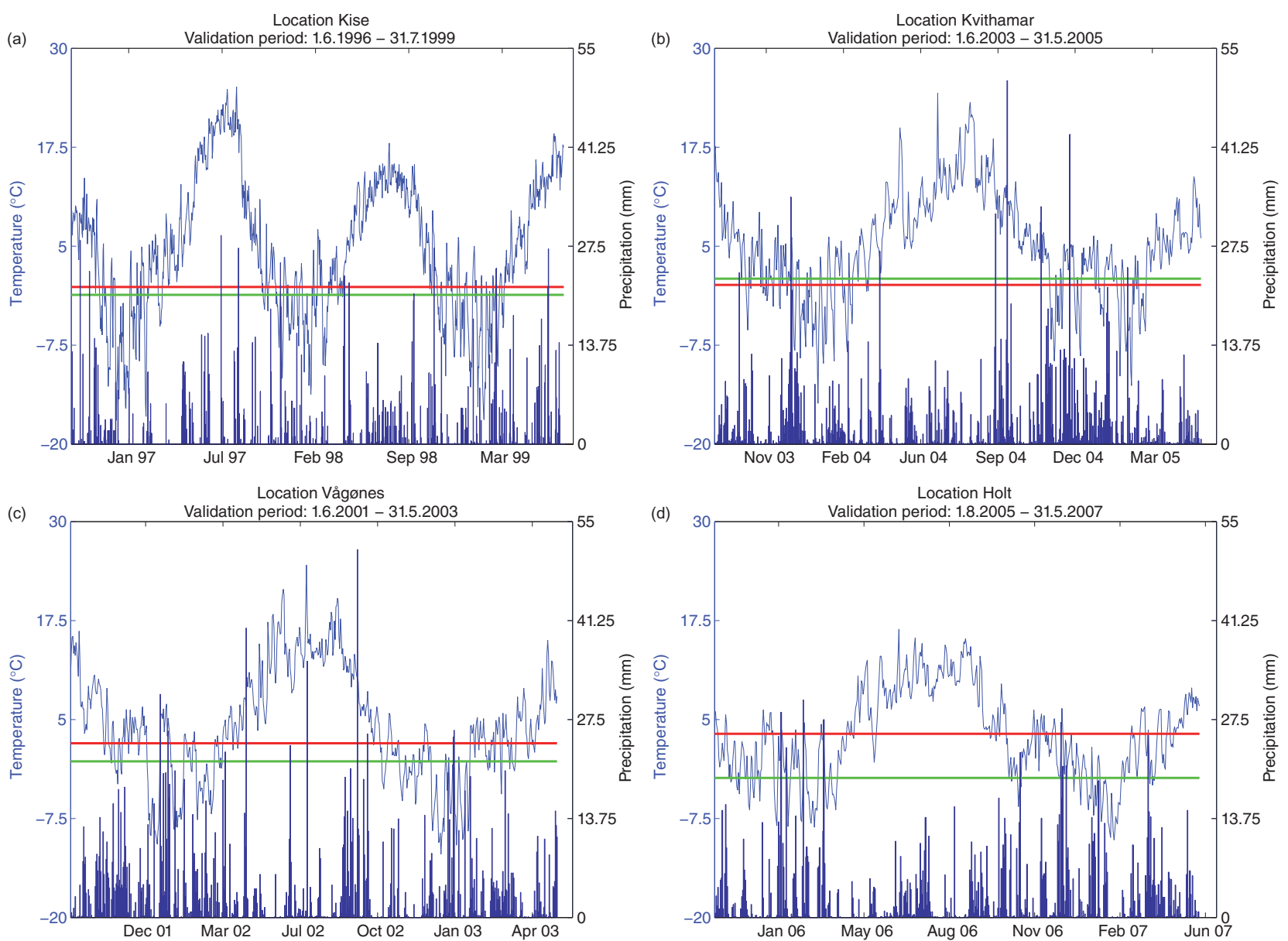

Fig. 4 Climate during validation period for locations (a) Kise, (b) Kvithamar, (c) Vågønes and (d) Holt. Solid lines show the daily mean air temperature $T_{\text {air }}$ (blue) and bars show daily precipitation; median values from the posterior distribution of the threshold temperatures for precipitation $T_{\text {rs }}$ (red) and snowmelt/refreezing $T_{\text {mf }}$ (green). See Table 7 for parameter values.

ice cover. We calibrated the model by means of welldocumented Bayesian methods, and conducted a qualitative sensitivity analysis. As far as we know this practice is still relatively new for this kind of model. The results presented here, both regarding assumptions about prior pdfs and the resulting posterior pdfs, and the simple yet very effective method of sensitivity analysis, are useful for the modelling community.

A study comparing four models simulating soil frost (Kennedy \& Sharratt 1998)-the two finite difference models SHAW and SOIL, and two energy balance models-concluded that the simpler energy balance models generally overestimate frost depth. However, one weakness of the models (investigated by Kennedy $\delta$ Sharratt) that also simulate snow cover is the estimation of snow depth. Snow cover has a strong influence on the estimation of soil frost depth, e.g., through snow depth and snow density, both affecting the thermal conductivity of the snow cover. Therefore, accurate simulation of snow cover is important for the simulation of soil frost depth.

Our new model SnowFrostIce for simulating the effects of winter climate on the soil surface is designed to be included in a grassland model. This restricts SnowFrostIce with regards to the number of parameters included. We calibrated SnowFrostIce against independent data from four locations in Norway, capturing climatic variation from south to north and from coastal to inland areas. We also identified the key parameters by conducting a sensitivity analysis.

It is important to bear in mind that SnowFrostIce represents simplifications of real-world processes, which are described at various levels of complexity. Some of the parameters used have a physical interpretation, but they are seldom measured, and quantitative data are scarce in the literature. This means that the parameters, and thereby the model outputs, are subject to uncertainty. 

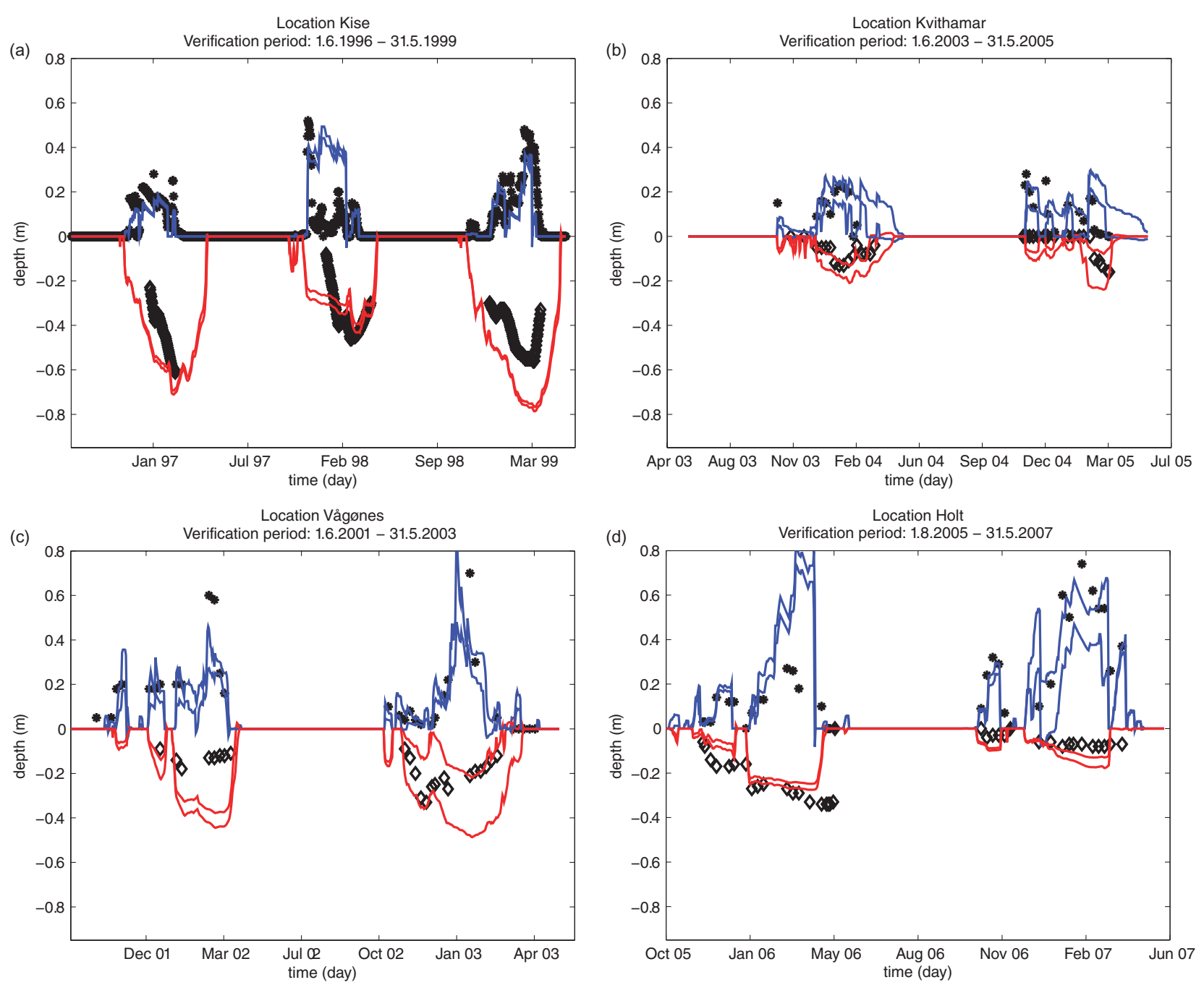

Fig. 5 Validation of the SnowFrostlce model describing the variation between model output and observed values on depths of snow and soil frost at (a) Kise, (b) Kvithamar, (c) Vågønes and (d) Holt. Solid lines (mean \pm SD) show $S_{\text {depth }}\left(\right.$ blue) and $F_{\text {depth }}$ (red); observed snow cover depth ( $*$ ); observed lower frost boundary $(\diamond)$.

The Bayesian method we used aims to quantify and reduce these uncertainties, rather than maximizing the model fit. When selecting an optimal parameter set for a simulation run for a specific location, we chose the parameter values that maximized the posterior distribution $\boldsymbol{\theta}_{\mathrm{MAP}}$ (Table 7 ). A consequence of this procedure was that these specific parameter values must be interpreted accordingly (i.e. reducing model uncertainty), rather than given a clear-cut physical interpretation.

When carrying out the Bayesian calibration, it was difficult to obtain convergence of the Markov chains for the parameters relating to liquid water in the snow cover $\left(S W_{\text {ret }}\right.$ and $\left.S W_{\text {rf }}\right)$. This may imply that the calibration data were not sufficient for improving the prior knowledge related to these parameters.
The estimated posterior distribution is different for each location. We expected some regional differences for the melting parameters $K_{\min }$ and $\Delta K_{\max }$ as a result of regional differences in radiation, altitude ( $\mathrm{m}$ a.s.l.) and ocean vicinity, for example, but not for the threshold temperatures for precipitation $T_{\mathrm{rs}}$ and snowmelt/refreezing $T_{\mathrm{mf}}$, or for the density of new snow $\rho_{\text {ns. }}$. This might indicate that the model needs geographical adjustments and a functional description of $\rho_{\mathrm{ns}}$. The differences in the results for the thermal conductivity of frozen soil $\lambda_{f s}$ were expected, as the soil types are different for each of the locations.

A reason for the erroneous estimation of $S_{\text {depth }}$ could be that the calibrated value of $T_{\mathrm{rs}}$ is wrong, leading to observed rain being simulated as snow, or vice versa. In addition, by using daily mean air temperatures, the model 
(a)

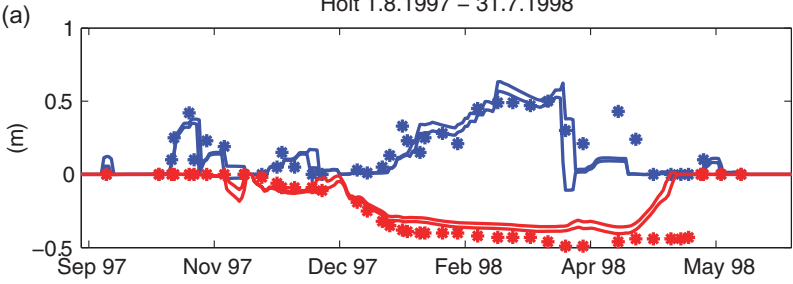

(b)

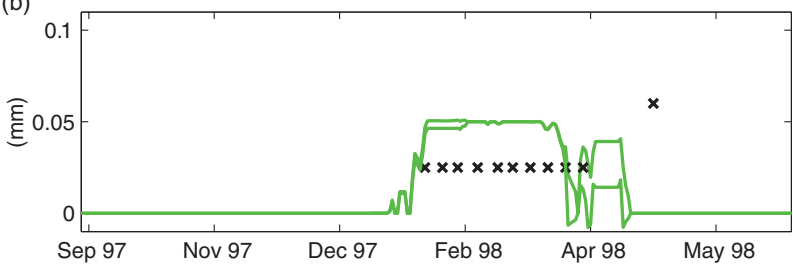

(c)

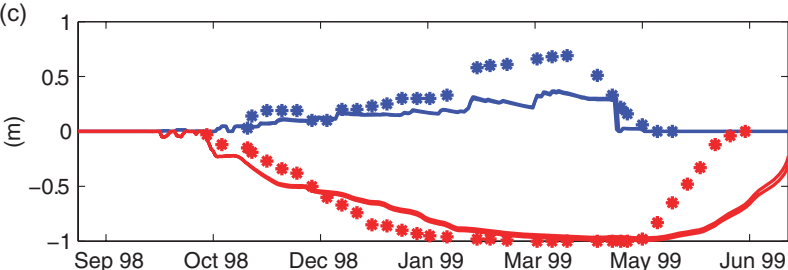

(d)

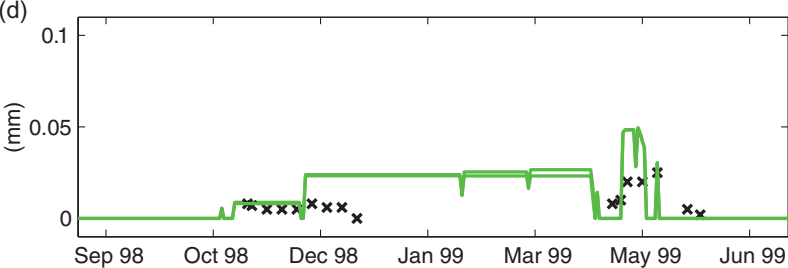

Fig. 6 Simulation results for (a, b) Holt and (c, d) Karasjok. In (a) and (c), solid lines show simulated values (mean \pm SD) and $(*)$ indicate observed values; blue represents snow cover, and red represents the lower frost boundary. In (b) and (d), solid green lines represent simulated (mean \pm SD) ice cover depth, and $(x)$ indicate observed values for ice cover depth.

might associate incorrect air temperatures with precipitation events. For instance, the observed air temperature could be below $0{ }^{\circ} \mathrm{C}$ for most of the day, followed by above $0^{\circ} \mathrm{C}$ at the end of the day, resulting in a mean daily temperature below $T_{\mathrm{rs}}$. If precipitation had been observed as rain by the end of the day, it would still have been simulated as snow. The overestimation of $S_{\text {depth }}$ might result from important processes being omitted, e.g., the heat content of rain is not incorporated in the model, so this kind of additional snowmelt is not included. A third reason for the erroneous estimation of $S_{\text {depth }}$ might be the redistribution of snow by wind, a factor not taken into account in the model.

The number of available observations for the calibration is important. Using data from two and three years is not sufficient to capture the interannual variation in snow cover and soil frost. The limited number of observations on both snow cover and soil frost at the same location has an effect on the results of the calibration. In a preliminary study, the snow module of SnowFrostIce was calibrated for the Kise location using two, four, six, eight and finally 10 years of snow depth observations (Roer et al. unpubl. ms.). Including more data resulted in a narrower posterior distribution, but convergence was also increasingly harder to obtain. Including more observations also resulted in a shift in the location of the posterior parameter distribution. This showed that the interannual variation in winter weather will affect the results of the calibration. As long as more data are included, the results are likely to keep varying until the whole spectrum of weather conditions is included. Ideally, we should have had observations comprising a full climate period (30 years) to capture the variation within a normal period. In the study comparing 33 snowpack models by Rutter et al. (2009) only two years of observations were available. In the present study, the data set was split in two in order to conduct the validation, which would otherwise have had to be postponed until more observations became available.

The parameters related to snowmelt $\left(T_{\mathrm{mf}}, K_{\mathrm{min}}\right.$ and $\left.\Delta K_{\max }\right)$ are less uncertain for Kise than for the other locations (see Fig. 3). This contributes to less uncertainty in the snow depth simulation at Kise compared with the other locations. At Kvithamar, in addition to the uncertainty of $T_{\mathrm{mf}}$, this parameter also has a high numerical value compared with the other locations (Table 7 ). This leads to more uncertainty in the melting period at Kvithamar, and also to a delayed onset of snowmelt in the simulations compared with, for example, Kise. The results from the sensitivity analysis showed that $T_{\mathrm{mf}}$ and $K_{\min }$ were the most important parameters related to snowmelt. It is therefore reasonable to attribute the uncertainty and delay in snowmelt mainly to the uncertainty of the parameters $T_{\mathrm{mf}}$ and $K_{\mathrm{min}}$.

In this study we used the likelihood of a sampled parameter set, given the data (see Eqn. 20), as a scalar output when calculating the sensitivity indices $\boldsymbol{\mu}^{*}$ and $\boldsymbol{\sigma}$. If, on the other hand, we were to use daily simulated snow depth values as the scalar output in the SA, for example, we would have to calculate one pair of $\mu^{*}$ and $\sigma$ for each of these $S_{\text {depth }}$ values. This would provide an answer to the question of which parameters were most important on which day during the whole simulation period. However, performing two SA-where the first SA uses depth of snow cover on a specific day during midwinter, and the second SA uses depth of snow cover on a specific day towards the end of winter-might give further indications 


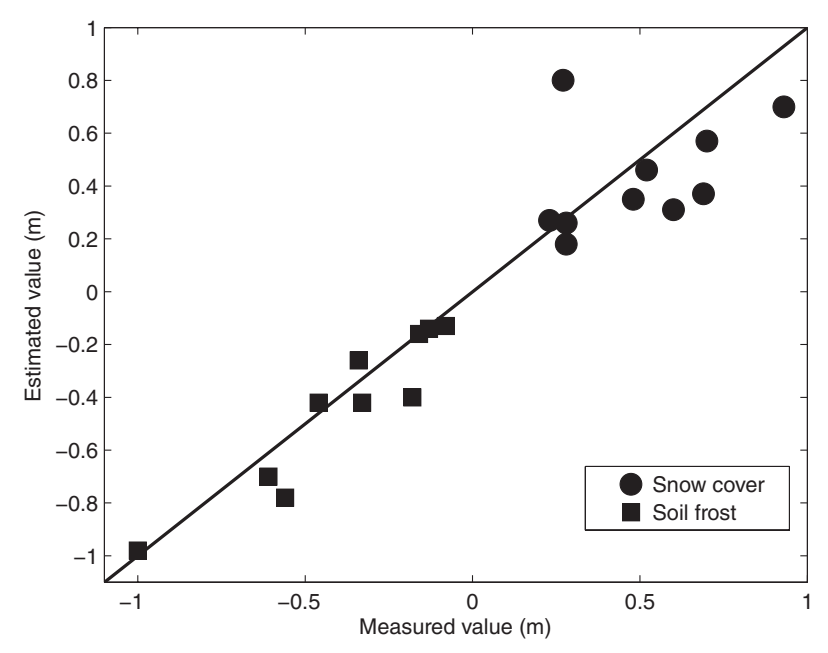

Fig. 7 Collective scatterplot of measured and estimated maximum values of the depths of snow cover $S_{\text {depth }}$ and soil frost $F_{\text {depth. }}$. Each point represents one independent set of data from the validation periods: three points correspond to Kise, two points each correspond to Kvithamar, Vågønes and Holt, and one point corresponds to Karasjok.

of which parameters are most important regarding snowmelt in cold and mild periods, respectively.

The purpose of our SA was to identify key parameters in the model. Here, we used the Morris screening method to identify the non-important parameters. In Fig. 1, the parameters $S W_{\mathrm{rf}} S W_{\text {ret }}$ and $\Delta K_{\max }$ are recognized as being less important (low values for $\mu^{*}$ and $\boldsymbol{\sigma}$ ). Following the way in which we defined parameter importance in our SA, the SA results suggest that varying these parameters within their prior bounds would not markedly affect the model output. We can also find support for this conclusion in the calibration results. Figure 3 shows that the posterior distribution for the three non-important parameters has not changed much compared with the prior distribution, implying that no new information is added through the data.

The ability of SnowFrostIce to simulate the maximum depths of snow cover and soil frost is presented in Fig. 7. The points lie close to the $1: 1$ line, indicating satisfactory model performance. The maximum depths of snow cover and soil frost are good indices to show the trends of the snow cover and soil freezing in each winter, and they are both appropriately estimated by the model.

The approach to calculating soil frost, by balancing energy, is similar to that proposed by Benoit $\delta$ Mostaghimi (1985). Although we made some critical assumptions (e.g., estimation of the soil surface temperature, a constant thermal conductivity of frozen soil and a constant thermal conductivity of snow), we have shown that when tested on independent data sets (see Fig. 7), the ability of SnowFrostIce to estimate the maximum lower frost boundary is also quite good.
The simulation of ice cover at Holt and Karasjok were based on the assumptions outlined in the sections "Puddle formation and infiltration of meltwater" and "Formation of ice layer". The results shown in Fig. 6 indicate that our simple approach is a sound starting point for further development of the ice layer module.

We conclude that our simple yet effective method for modelling depths of snow cover, lower frost boundary and soil surface ice provides reasonable results, making it suitable for incorporation into more complex models.

\section{Continued work}

In order to simulate damage to plants as a result of ice encasement, for example, there is a need for a better description of local field topography, such as quantifying the part of the study area that can potentially be covered by surface puddles. This will be of help when simulating the number of plants dying because of ice-related stresses. These refinements should be followed by further model validation.

The results from the calibration and SA indicate scope for model improvement. A modification motivated by the calibration results is a functional description of $\rho_{\text {ns }}$. In addition, the results from the SA suggest lumping together (or disregarding) the processes related to liquid water within the snow cover, and replacing the sinusoidal snowmelt function by a constant melt rate.

\section{Acknowledgements}

Comments from Dr Mats Höglind were much appreciated. This study was funded by the Norwegian Research Council as part of the programme WINSUR. The authors are grateful to the two anonymous reviewers for their insightful comments on an earlier version of this manuscript.

\section{References}

Baker J. \& Spaans E.J.A. 1997. Mechanics of meltwater movement above and within frozen soil. In I. Iskandar et al. (eds.): Proceedings of the International Symposium on Physics, Chemistry, and Ecology of Seasonally Frozen Soils, Fairbanks, Alaska, June 10-12, 1997. CRRL Special Report 97-10. Pp. 31-36. Hanover, NH: US Army Cold Regions Research and Engineering Laboratory.

Bélanger G., Rochette P., Gastonguay Y., Bootsma A., Mongrain D. \& Ryan D. 2002. Climate change and winter survival of perennial forage crops in eastern Canada. Agronomy Journal 94, 1120-1130.

Beldring S., Engen-Skaugen T., Forland E. \& Roald L. 2008. Climate change impacts on hydrological processes in 
Norway based on two methods for transferring regional climate model results to meteorological station sites. Tellus Series A 60, 439-450.

Benoit G. \& Mostaghimi S. 1985. Modeling soil frost depth under three tillage systems. Transactions of the ASAE 28, 1499-1505.

Campolongo F., Cariboni J. \& Saltelli A. 2007. An effective screening design for sensitivity analysis of large models. Environmental Modelling and Software 22, 1509-1518.

Campolongo F., Tarantola S. \& Saltelli A. 1999. Tackling quantitatively large dimensionality problems. Computer Physics Communications 117, 75-85.

DeGaetano A., Cameron M. \& Wilks D. 2001. Physical simulation of maximum seasonal soil freezing depth in the United States using routine weather observations. Journal of Applied Meteorology 40, 546-555.

Engeset R., Sorteberg H. \& Udnæs H. 2000. NOSIT—utvikling av NVEs operasjonelle snøinformasjonstjeneste. (NOSITdevelopment of the operational snow information services of NVE.) Dokument 1. Olso: Norwegian Water Resources and Energy Directorate.

Flerchinger G. \& Saxton K. 1989. Simultaneous heat and water model of a freezing snow-residue-soil system. I. Theory and development. Transactions of the ASAE 32, 565-571.

Gelman A. 1996. Interference and monitoring convergence. In W.R. Gilks et al. (eds.): Markov chain Monte Carlo in practice. Pp. 131-144. Suffolk: Chapman \& Hall.

Gelman A. \& Rubin D. 1992. Inference from iterative simulation using multiple sequences (with discussion). Statistical Science 7, 457-511.

Gray J. \& Morland L. 1995. The compaction of polar snow packs. Cold Regions Science and Technology 23, 109-119.

Gudleifsson B. \& Larsen A. 1993. Advances in plant cold hardiness. Boca Raton, FL: CRC Press.

Hayashi M., van Der Kamp G. \& Schmidt R. 2003. Focused infiltration of snowmelt water in partially frozen soil under small depressions. Journal of Hydrology 270, 214-229.

Höglind M., Schapendonk A. \& van Oijen M. 2001. Timothy growth in Scandinavia: combining quantitative information and simulation modelling. New Phytologist 151, 355-367.

Iwata Y., Hayashi M. \& Hirota T. 2008. Comparison of snowmelt infiltration under different soil-freezing conditions influenced by snow cover. Vadose Zone Journal 7, 79-86.

Jansson P. \& Karlberg L. 2001. Coupled heat and mass transfer model for soil-plant-atmosphere systems. Stockholm: Department of Civil and Environmental Engineering, Royal Institute of Technology.

Jordan R. 1991. A one-dimensional temperature model for a snow cover. Technical documentation for SNTHERM.89. CRRL Special Report 91-16. Hanover, NH: US Army Cold Regions Research and Engineering Laboratory.

Judson A. \& Doesken N. 2000. Density of freshly fallen snow in the central Rocky Mountains. Bulletin of the American Meteorological Society 81, 1577-1587.
Kennedy I. \& Sharratt B. 1998. Model comparisons to simulate soil frost depth. Soil Science 163, 636-645.

Kokkonen T., Koivusalo H., Jakeman T. \& Norton J. 2006. Construction of a degree-day snow model in the light of the ten iterative steps in model development. In A. Voinov et al. (eds.): Proceedings of the iEMSS Third Biennial Meeting: Summit on Environmental Modelling and Software. Environmental Modelling and Software Society, Burlington, USA, July 2006. CD-ROM. Manno, Switzerland: International Environmental Modelling and Software Society.

Larsen A. 1994. Breeding winter hardy grasses. Euphytica 77, 231-237.

Melloh R. 1999. A synopsis and comparison of selected snowmelt algorithms. CRRL Report 99-8. Hanover, NH: US Army Cold Regions Research and Engineering Laboratory.

Roberts G.O. 1996. Markov chain concepts related to sampling algorithms. In W.R. Gilks et al. (eds.): Markov chain Monte Carlo in practice. Pp. 45-57. Suffolk: Chapman \& Hall.

Rutter N., Essery R., Pomeroy J., Altimir N., Andreadis K., Baker I., Bartlett P., Boone A., Deng H., Douville H., Dutra E., Elder K., Ellis C., Feng X., Gelfan A., Goodbody A., Gusev Y., Gustafsson D., Hellström R., Hirabayashi Y., Hirota T., Jonas T., Koren V., Kuragina A., Lettenmaier D., Li W.-P., Luce C., Martin E., Nasonova O., Pumpanen J., Pyles R.D., Samuelsson P., Sandells M., Schädler G., Shmakin A., Smirnova T.G., Stähli M., Stöckli R., Strasser U., Su H., Suzuki K., Takata K., Tanaka K., Thompson E., Vesala T., Viterbo P., Wiltshire A., Xia K., Xue Y. \& Yamazaki T. 2009. Evaluation of forest snow process models (SnowMIP2). Journal of Geophysical Research-Atmospheres 114, D06111, doi: 10.1029/ 2008JD011063.

Saltelli A., Ratto M., Andres T., Campolongo F., Cariboni J., Gatelli D., Saisana M. \& Tarantola S. 2008. Global Sensitivity Analysis. The primer. West Sussex: Wiley \& Sons.

Sivia D. 2006. Data analysis: A Bayesian tutorial. 2nd edn. Oxford: Oxford University Press.

Stähli M., Bayard D., Wydler H. \& Fluhler H. 2004. Snowmelt infiltration into alpine soils visualized by dye tracer technique. Arctic, Antarctic, and Alpine Research 36, 128-135.

Thorsen S.M. \& Haugen L.E. 2007. Development of the SnowFrost model for the simulation of snow fall and soil frost. Bioforsk FOKUS 2(9). Ås, Norway: Bioforsk.

van Oijen M., Höglind M., Hanslin H. \& Caldwell N. 2005. Process-based modelling of timothy regrowth. Agronomy Journal 97, 1295-1303.

van Oijen M., Rougier J. \& Smith R. 2005. Bayesian calibration of process-based forest models: bridging the gap between models and data. Tree Physiology 25, 915-927.

Vehvilainen B. 1992. Snow cover models in operational watershed forecasting. PhD thesis, Helsinki University of Technology. 


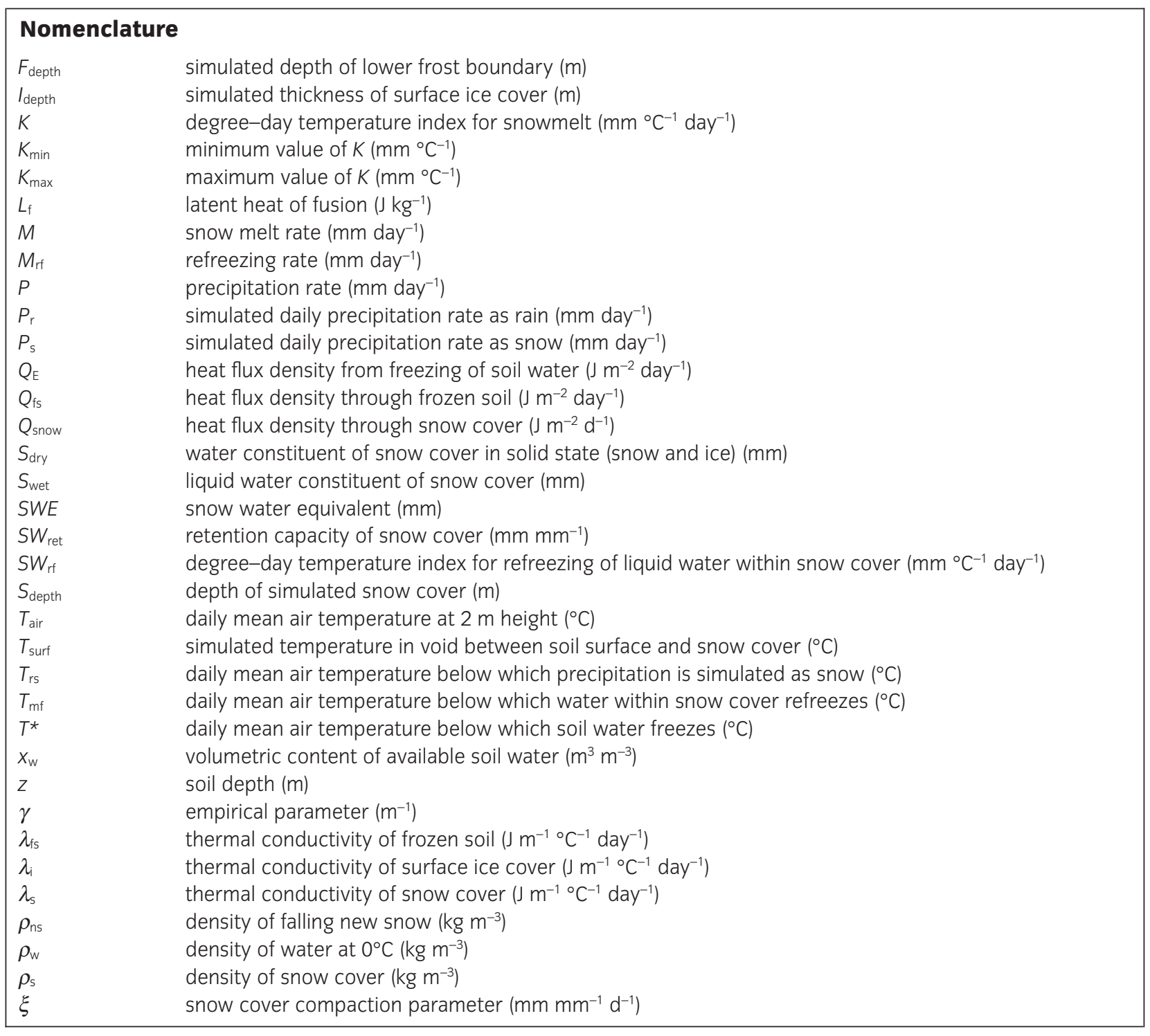

